\title{
Reward-Related Ventral Striatum Activity Buffers against the Experience of Depressive Symptoms Associated with Sleep Disturbances
}

\author{
@Deut Avinun, ${ }^{1}$ Adam Nevo, ${ }^{2}$ Annchen R. Knodt, ${ }^{1}$ CMaxwell L. Elliott, ${ }^{1}$ Spenser R. Radtke, ${ }^{1}$ Bartholomew D. Brigidi, ${ }^{1}$ \\ and Ahmad R. Hariri ${ }^{1}$ \\ ${ }^{1}$ Laboratory of NeuroGenetics, Department of Psychology and Neuroscience, Duke University, Durham, North Carolina 27705, and ${ }^{2}$ Cardiothoracic \\ Division, Department of Surgery, Duke University Medical Center, Durham, North Carolina 27710
}

Sleep disturbances represent one risk factor for depression. Reward-related brain function, particularly the activity of the ventral striatum (VS), has been identified as a potential buffer against stress-related depression. We were therefore interested in testing whether reward-related VS activity would moderate the effect of sleep disturbances on depression in a large cohort of young adults. Data were available from 1129 university students (mean age $19.71 \pm 1.25$ years; 637 women) who completed a reward-related functional MRI task to assay VS activity and provided self-reports of sleep using the Pittsburgh Sleep Quality Index and symptoms of depression using a summation of the General Distress/Depression and Anhedonic Depression subscales of the Mood and Anxiety Symptoms Questionnaireshort form. Analyses revealed that as VS activity increased the association between sleep disturbances and depressive symptoms decreased. The interaction between sleep disturbances and VS activity was robust to the inclusion of sex, age, race/ethnicity, past or present clinical disorder, early and recent life stress, and anxiety symptoms, as well as the interactions between VS activity and early or recent life stress as covariates. We provide initial evidence that high reward-related VS activity may buffer against depressive symptoms associated with poor sleep. Our analyses help advance an emerging literature supporting the importance of individual differences in reward-related brain function as a potential biomarker of relative risk for depression.

Key words: depression; reward; risk; sleep disturbance; ventral striatum

Significance Statement

Sleep disturbances are a common risk factor for depression. An emerging literature suggests that reward-related activity of the ventral striatum (VS), a brain region critical for motivation and goal-directed behavior, may buffer against the effect of negative experiences on the development of depression. Using data from a large sample of 1129 university students we demonstrate that as reward-related VS activity increases, the link between sleep disturbances and depression decreases. This finding contributes to accumulating research demonstrating that reward-related brain function may be a useful biomarker of relative risk for depression in the context of negative experiences.

\section{Introduction}

Depression is a leading cause of disability in the developed world, being responsible for $\sim 4 \%$ of global disease burden worldwide (Whiteford et al., 2013), thus making the improvement of treatment and prevention methods a priority. Poor sleep is one of the more common risk factors for depression and has been implicated in numerous other negative physical health outcomes such

\footnotetext{
Received June 21, 2017; revised Aug. 22, 2017; accepted Aug. 25, 2017.

Author contributions: R.A., A.N., B.D.D., and A.R.H. designed research; A.R.K, S.R.R., B.D.B, and A.R.H. performed research; R.A., A.R.K., M.L.E., and S.R.R. analyzed data; R.A., A.N., A.R.K., M.L.E., and A.R.K., wrote the paper.

This work was supported by Duke University and National Institutes of Health (NIH) Grants R01DA033369 and R01DA031579 to the Duke Neurogenetics Study; NIH Grant R01AG049789 to R.A., A.R.K., and A.R.H.; and the National Science Foundation Graduate Research Fellowship, Grant NSF DGE-1644868 to M.L.E. We thank the Duke Neurogenetics Study participants and the staff of the Laboratory of NeuroGenetics.

The authors declare no competing financial interests.
}

as chronic pain, cardiovascular and respiratory illness, and immune dysregulation (Taylor et al., 2003; Baglioni et al., 2011; Harvey et al., 2011; Sofi et al., 2014). Both insomnia and hypersomnia are symptoms of depression, but insomnia appears to be more prevalent and more strongly associated with the onset, severity, and recurrence of major depressive episodes (Manber and Chambers, 2009; Baglioni et al., 2011). Further evidence linking poor sleep and depression comes from treatment studies wherein alleviating sleep problems is associated with a concurrent decrease in depression (Fava et al., 2006; Manber et al., 2008). No-

Correspondence should be addressed to Dr. Reut Avinun, Laboratory of NeuroGenetics, Department of Psychology and Neuroscience, Duke University, Grey Building 2020 West Main Street, Suite 0030, Durham, NC 27705. E-mail: reut.avinun@duke.edu.

DOI:10.1523/JNEUROSCI.1734-17.2017

Copyright $\odot 2017$ the authors $\quad 0270-6474 / 17 / 379724-06 \$ 15.00 / 0$ 
tably, poor sleep does not always lead to the onset of depression, suggesting that other factors, both intrinsic and extrinsic, may modulate this association as has been reported for other forms of common stressors (Caspi et al., 2003; Abela and Skitch, 2007; Nikolova et al., 2012; Wang et al., 2014).

Individual differences in brain function have emerged as a particularly important potential moderator of psychopathology, as they represent not only treatment targets but also risk biomarkers (Beck, 2008; Admon et al., 2013; Strawn et al., 2014). Although much early research focused on the contributions of variability in threat-related amygdala activity to depression, there has been increasing recent emphasis on individual differences in the ventral striatum (VS), which functions as a central neural hub supporting goal-directed behaviors and reward processing. For example, relatively blunted reward-related VS activity has been associated with depression (Epstein et al., 2006; Hanson et al., 2015), and deep brain stimulation targeting the VS has an antidepressant effect in patients with treatment resistant or severe depression (Schlaepfer et al., 2008; Malone et al., 2009; Bewernick et al., 2010). Previous research has further demonstrated that reward-related traits increase resilience to stress (Corral-Frías et al., 2016), and that high reward-related VS activity may buffer against the effect of negative experiences on the development of depressive symptoms (Nikolova et al., 2012; Corral-Frías et al., 2015).

In the current study, we examined whether reward-related VS activity modulate the association between poor sleep and the experience of depressive symptoms in a large cohort of young adult volunteers. Based on the work summarized above, we predicted that variability in VS activity, assayed with functional MRI (fMRI), would significantly interact with sleep, as indexed by self-report using the Pittsburgh Sleep Quality Index, to predict depressive symptoms, as identified by self-report using the Mood and Anxiety Symptoms Questionnaire. More specifically, we hypothesized that poor sleep would be more strongly associated with depressive symptoms in individuals with relatively low reward-related VS activity.

\section{Materials and Methods}

Participants and study design. Data were derived from 1330 participants (762 women; mean age $19.70 \pm 1.25$ years) who successfully completed the Duke Neurogenetics Study (DNS), which assessed a range of behavioral and biological traits among young adult, university students. The DNS was approved by the Duke University School of Medicine Institutional Review Board, and all participants provided written informed consent before participation. Detailed recruitment and exclusion criteria have been reported previously (Prather et al., 2013; Swartz et al., 2015). As described below, the current analyses were conducted on data available for a subset of 1129 participants (637 women; mean age $19.71 \pm 1.25$ years). Based on self reports there were 515 non-Hispanic Caucasians, 119 African-Americans, 304 Asian-Americans, 75 Latino/as, 2 Pacific Islanders, and 114 multiracial or other participants in this final sample.

As the DNS seeks to examine the broad distribution of dimensional behavioral and biological variables, any past or current DSM-IV Axis I disorder or select Axis II disorders (antisocial personality disorder and borderline personality disorder) was not an exclusion to participation. However, no individuals, regardless of diagnosis, were taking any psychoactive medication during or at least $14 \mathrm{~d}$ before their participation. Categorical diagnosis was assessed with the electronic Mini International Neuropsychiatric Interview (Lecrubier et al., 1997) and Structured Clinical Interview for the DSM-IV subtests (First et al., 1996). Of the 1129 participants used in our analyses, 236 individuals had at least one DSM-IV diagnosis, including 121 with alcohol use disorders, 43 with non-alcohol substance use disorders, 64 with major depressive disorders, 32 with bipolar disorders, 24 with panic disorder (no agoraphobia), 21 with panic disorder including agoraphobia, 11 with social anxiety disorder,
20 with generalized anxiety disorder, 13 with obsessive compulsive disorder, 10 with eating disorders, and 2 with post-traumatic stress disorder.

Race/ethnicity. Because self-reports of race and ethnicity are not always accurate and whole-genome data were available, an analysis of identity by state of whole-genome single nucleotide polymorphisms was performed in PLINK (Purcell et al., 2007). The first four multidimensional scaling components were used as covariates to reduce possible confounding effects of ancestry in our primary analyses.

Sleep disturbances. Self-reported sleep disturbances were assessed using an adapted version of the Pittsburgh Sleep Quality Index (PSQI; Buysse et al., 1989). The PSQI is a widely used measure of sleep disturbances over the past 1 month. It is based on 19 items, which yield seven component scores that reflect the frequency of sleep problems in the following areas: subjective sleep quality, sleep latency, sleep duration, habitual sleep efficiency, sleep disturbance, use of sleep medication, and daytime dysfunction. The components are summed to yield a global score that ranges from 0 to 21 , with poorer sleep quality associated with a higher score. A PSQI global score $>5$ has routinely been used to distinguish "poor" from "good" sleepers (Buysse et al., 1989). In our final sample, $35 \%$ of participants were characterized as "poor sleepers".

Stress. Because we previously showed that early and recent life stress interact with reward-related VS activity to predict anhedonic symptoms (Nikolova et al., 2012; Corral-Frías et al., 2015), we controlled for possible effects of early life stress using the Childhood Trauma Questionnaire (CTQ; Bernstein et al., 2003) and for recent life stress using the Life Events Scale for Students (LESS; Clements and Turpin, 1996). We also controlled for the interactions between early and recent life stress and VS activity in our model. The Cronbach's $\alpha$ for the 28 -item CTQ was 0.70 , and all items were consequently summed to create a total score of early life stress. For recent life stress, we summed the 38 negatively valenced items $(\alpha=0.66)$ from the LESS, which are more consistent with the negative experience of sleep disturbances.

Depression and anxiety. We assessed symptoms of depression in the past week before study participation using the Mood and Anxiety Symptom Questionnaire-short form (MASQ; Watson and Clark, 1991). The MASQ includes 4 subscales: the General Distress/Depression (GDD), Anhedonic Depression (AD), General Distress/Anxiety (GDA), and Anxious Arousal (AA). The GDA subscale includes 11 items assessing negative emotion relating to anxiety. The AA includes 17 items assessing physiological hyperarousal relating to anxiety (e.g., shaky hands, shortness of breath). The two anxiety subscales were summed and used a covariate in our models. The GDD subscale includes 12 items reflecting negative mood. The 22-item AD subscale is an instrument assessing lack of positive mood, loss of interest in activities, and low energy. One item was excluded from this questionnaire in our sample ("thoughts about death or suicide") to be compliant with the Duke University IRB. Notably both depression subscales do not include items evaluating sleep quality. The two depression subscales were summed to create a depression score. In the DNS, the Cronbach's $\alpha$ for the subscales were 0.84 for GDA, 0.89 for AA, 0.93 for GDD, and 0.91 for AD.

fMRI task. Our blocked design consisted of a pseudorandom presentation of trials wherein participants played a card-guessing game resulting in fixed positive or negative feedback for each trial. Subjects were told that their performance on the card game would determine a monetary reward to be received at the end of the game. During each trial, subjects had $3 \mathrm{~s}$ to guess, via button press, whether the value of an upcoming visually presented card would be lower or $>5$ (index and middle finger, respectively). After a choice was made, the numerical value of the card was presented (higher or lower) for $500 \mathrm{~ms}$ and followed by appropriate feedback (green upward-facing arrow for positive feedback; red downwardfacing arrow for negative feedback) for an additional $500 \mathrm{~ms}$. A crosshair focus point was then presented for $3 \mathrm{~s}$ for a total trial length of $7 \mathrm{~s}$. Each task block was comprised of five trials, with three blocks each of predominantly positive feedback ( $80 \%$ correct) and three of predominantly negative feedback (20\% correct). We included an incongruent trial type within each task block (e.g., 1 of 5 trials during positive feedback blocks was incorrect, resulting in negative feedback) to prevent subjects from anticipating the feedback for each trial and maintain subject's engagement and motivation to perform well. The positive and negative feedback 
blocks were interleaved with three control blocks. During control blocks, subjects were instructed to simply make alternating button presses during the presentation of an " $\mathrm{x}$ " ( $3 \mathrm{~s})$, which was followed by an asterisk $(500 \mathrm{~ms})$ and a yellow circle $(500 \mathrm{~ms})$. Each block was preceded by an instruction of "Guess Number" (positive or negative feedback blocks) or "Press button" (control blocks) for $2 \mathrm{~s}$ resulting in a total block length of $38 \mathrm{~s}$ and a total task length of $342 \mathrm{~s}$. Subjects were unaware of the fixed outcome probabilities associated with each block and were led to believe that their performance would determine their net monetary gain, although all subjects received $\$ 10$ upon completion of the task. As we have done in our prior work (Nikolova et al., 2012, 2013; Carré et al., 2013; Corral-Frías et al., 2015; Victor et al., 2015; Baranger et al., 2016), we focused on the contrast of positive feedback $>$ negative feedback blocks, which produces localized reward-related VS activity, rather than more general striatal activity produced by the contrasts of positive feedback $>$ control and negative feedback > control (Hariri et al., 2006).

fMRI data acquisition and analysis. Each participant was scanned using one of two identical research-dedicated GE MR750 3T scanners equipped with high-power high-duty-cycle $50 \mathrm{mT} / \mathrm{m}$ gradients at 200 $\mathrm{T} / \mathrm{m} / \mathrm{s}$ slew rate, and an 8-channel head coil for parallel imaging at high bandwidth up to $1 \mathrm{MHz}$ at the Duke-UNC Brain Imaging and Analysis Center. A semiautomated high-order shimming program was used to ensure global field homogeneity. A series of 34 interleaved axial functional slices aligned with the anterior commissure-posterior commissure plane were acquired for full-brain coverage using an inverse-spiral pulse sequence to reduce susceptibility artifacts (TR/TE/flip angle $=2000$ $\mathrm{ms} / 30 \mathrm{~ms} / 60 ; \mathrm{FOV}=240 \mathrm{~mm} ; 3.75 \times 3.75 \times 4 \mathrm{~mm}$ voxels; interslice skip $=0$ ). Four initial radiofrequency excitations were performed (and discarded) to achieve steady-state equilibrium. To allow for spatial registration of each participant's data to a standard coordinate system, high-resolution three-dimensional T1-weighted structural images were obtained in 162 axial slices using a 3D Ax FSPGR BRAVO sequence $\left(\mathrm{TR} / \mathrm{TE} / \mathrm{flip}\right.$ angle $=8.148 \mathrm{~ms} / 3.22 \mathrm{~ms} / 12^{\circ}$; voxel size $=0.9375 \times$ $0.9375 \times 1 \mathrm{~mm}$; FOV $=240 \mathrm{~mm}$; interslice skip $=0$; total scan time $=$ $4 \mathrm{~min}, 13 \mathrm{~s}$ ). For participants without a high-quality Ax FSPGR BRAVO images $(n=24)$, high-resolution structural images acquired in 34 axial slices coplanar with the functional scans (TR/TE/flip angle $=7.7 \mathrm{~s} / 3.0$ $\mathrm{ms} / 12$; voxel size $=0.9 \times 0.9 \times 4 \mathrm{~mm} ; \mathrm{FOV}=240 \mathrm{~mm}$, interslice skip $=$ $0)$ were used for spatial registration.

$B O L D$ fMRI data preprocessing. Anatomical images for each subject were skull-stripped, intensity-normalized, and nonlinearly warped to a study-specific average template in the standard stereotactic space of the Montreal Neurological Institute template using ANTs (Klein et al., 2009). BOLD time series for each subject were processed in AFNI (Cox, 1996). Images for each subject were despiked, slice-time-corrected, realigned to the first volume in the time series to correct for head motion, coregistered to the anatomical image using FSL's Boundary Based Registration (Greve and Fischl, 2009), spatially normalized into MNI space using the nonlinear warp from the anatomical image, resampled to $2 \mathrm{~mm}$ isotropic voxels, and smoothed to minimize noise and residual difference in gyral anatomy with a Gaussian filter set at $6 \mathrm{~mm}$ full-width at half-maximum. All transformations were concatenated so that a single interpolation was performed. Voxelwise signal intensities were scaled to yield a time series mean of 100 for each voxel. Volumes exceeding $0.5 \mathrm{~mm}$ framewise displacement or 2.5 standardized DVARS (temporal derivative of RMS variance over voxels; Power et al., 2014; Nichols, 2017) were censored from the GLM.

fMRI quality assurance criteria. Quality control criteria for inclusion of a participant's imaging data were as follows: $>5$ volumes for each condition of interest retained after censoring for framewise displacement and DVARS and sufficient temporal SNR within $5 \mathrm{~mm}$ bilateral ventral striatum spheres centered at $( \pm 12,10,-10)$, defined as $>3$ SD below the mean of this value across subjects. Additionally, data were only included in further analyses if the participant demonstrated sufficient engagement with the task, defined as responding to and receiving positive or negative feedback on at least $60 \%$ of trials within win and loss blocks, respectively. The highest percentage that could be achieved was $80 \%$, due to the incongruent trial in each block.

The AFNI program 3dREMLfit (Cox, 1996) was used to fit a general linear model for first-level fMRI data analyses. Following preprocessing,
Table 1. Descriptive statistics for the main variables and covariates $(N=1129)$

\begin{tabular}{lcccc}
\hline & Min & Max & Mean & SD \\
\hline Sleep disturbances & 0 & 17 & 4.98 & 2.62 \\
VS activity (centered) & -1.17 & 1.11 & 0 & 0.17 \\
Recent life stress & 0 & 18 & 2.55 & 2.43 \\
Early life stress & 25 & 76 & 33.43 & 8.72 \\
General distress/depression & 12 & 60 & 20.96 & 8.44 \\
Anhedonic depression & 21 & 99 & 51.89 & 12.87 \\
General distress/anxiety & 11 & 54 & 17.54 & 5.83 \\
Anxious arousal & 17 & 84 & 21.00 & 6.34 \\
\hline
\end{tabular}
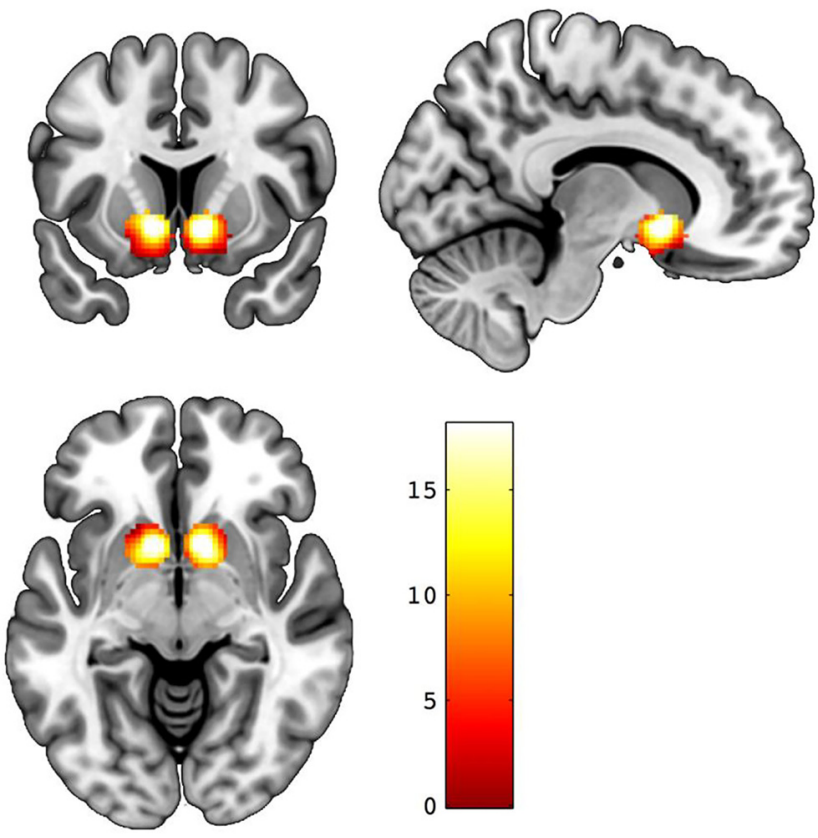

Figure 1. Reward-related VS activity. Statistical parametric maps illustrating bilateral VS activation clusters for the contrast positive feedback $>$ negative feedback. Activation clusters are overlaid onto canonical structural brain images. Color bar represents $t$ scores.

linear contrasts using canonical hemodynamic response functions were used to estimate differential effects of feedback (i.e., reward) from the contrast of positive feedback $>$ negative feedback for each individual. Individual contrast images were then used in second-level random effects models in SPM12 (RRID:SCR_007037; http://www.fil.ion.ucl.ac.uk/spm) accounting for scan-to-scan and participant-to-participant variability to determine mean condition-specific regional responses using one-sample $t$ tests. A statistical threshold of $p<0.05$, FWE-corrected across our VS regions-of-interest (spheres $10 \mathrm{~mm}$ in radius at approximately: $x= \pm 12$, $y=12, z=-10$ ), and $\geq 10$ contiguous voxels was applied to the positive feedback $>$ negative feedback contrast.

Mean BOLD values from the resulting VS clusters were extracted using the volume of interest tool in SPM12. These extracted values for the left and right VS were then averaged and used in the below analyses. Importantly, by extracting VS BOLD parameter estimates from the functional clusters activated by our task rather than clusters specifically correlated with our independent variables-of-interest, we preclude the possibility of any correlation coefficient inflation that may result when an explanatory covariate is used to select a region-of-interest (Viviani, 2010).

Statistical analyses. Mplus v7 (Muthén and Muthén, 2007) was used to conduct a regression analysis, with MASQ depressive symptoms (GDD and $\mathrm{AD}$ ) as the outcome. Mean VS activity values, LESS total scores, CTQ total scores, and sleep disturbances were grand mean centered before computing the interaction terms to avoid multicollinearity. Participant sex (coded as $1=$ male, 2 = female), age, categorical diagnosis (coded as $0=$ no diagnosis, $1=1$ or more diagnoses), race/ethnicity, LESS total scores, CTQ total score, anxiety (a sum of AA and GDA), the interaction 
Table 2. Predicting MASQ depressive symptoms scores with sleep disturbances, reward-related VS activity, and their interaction

\begin{tabular}{lcr}
\hline & \multicolumn{2}{l}{ Depressive symptoms } \\
\cline { 2 - 3 } & \multicolumn{1}{l}{$b(\mathrm{SE})$} & \multicolumn{1}{c}{$\beta(\mathrm{SE})$} \\
\hline Ethnicity 1 & $-4.005(10.203)$ & $-0.01(0.027)$ \\
Ethnicity 2 & $20.463(7.708)^{* *}$ & $0.063(0.024)$ \\
Ethnicity 3 & $-55.482(30.946)$ & $-0.05(0.028)$ \\
Ethnicity 4 & $-17.029(29.17)$ & $-0.012(0.021)$ \\
Sex & $0.352(0.917)$ & $0.009(0.024)$ \\
Age & $-0.583(0.364)$ & $-0.038(0.024)$ \\
Diagnosis & $1.31(1.237)$ & $0.028(0.026)$ \\
Early stress & $0.416(0.071)^{* *}$ & $0.19(0.033)$ \\
Recent stress & $-0.181(0.219)$ & $-0.023(0.028)$ \\
Anxiety & $0.533(0.052)^{* *}$ & $0.317(0.032)$ \\
VS activity & $2.585(2.418)$ & $0.024(0.022)$ \\
Sleep disturbances & $2.019(0.194)^{* *}$ & $0.277(0.027)$ \\
VS activity $\times$ sleep disturbances & $-2.441(0.848)^{* *}$ & $-0.065(0.024)$ \\
VS activity $\times$ recent stress & $0.758(1.012)$ & $0.021(0.028)$ \\
VS activity $\times$ early stress & $0.077(0.359)$ & $0.007(0.033)$ \\
\hline
\end{tabular}

${ }^{* *} p<0.01 . N=1129$

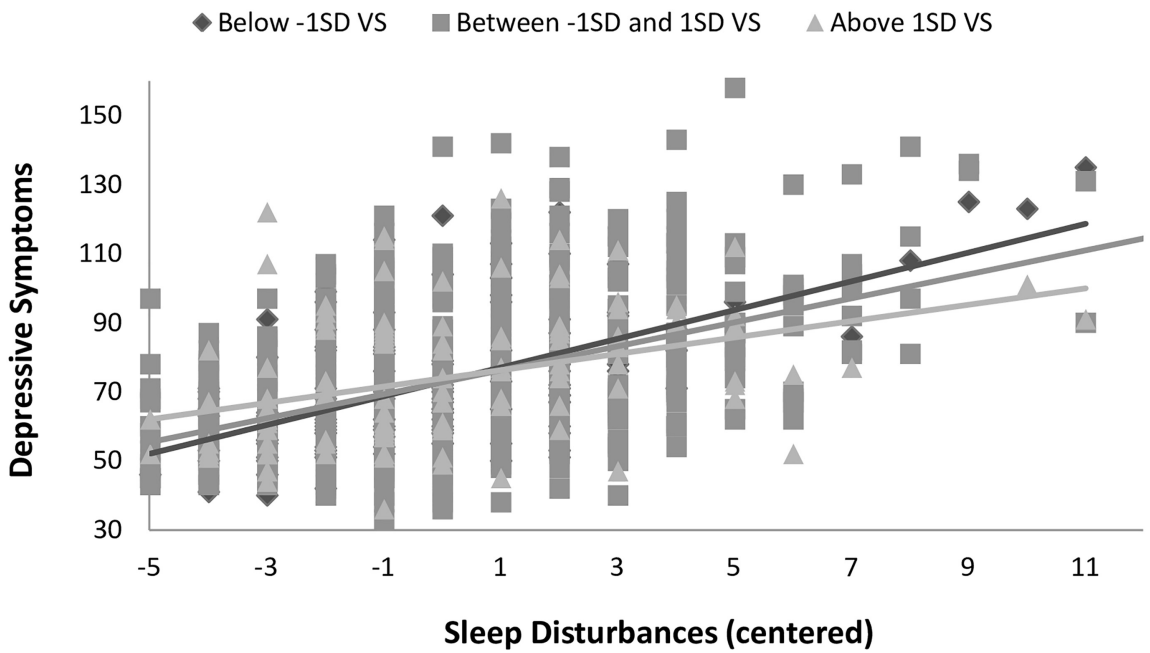

Figure 2. VS activity moderates the association between sleep disturbances and depressive symptoms. $72.91 \pm 19.06)$

$(b=2.02, \mathrm{SE}=0.19, p<0.001 ; b=0.53, \mathrm{SE}=0.05, p<0.001 ;$ $b=0.42, \mathrm{SE}=0.07, p<0.001$, respectively). There was a main effect of race/ethnicity on depressive symptoms with higher scores for self-reported Asian-American and African-American subsamples in comparison with self-reported non-Hispanic Caucasians (Caucasians: $70.38 \pm 17.88$; African-Americans: $76.86 \pm 21.59$; $75.80 \pm 19.79$; Latino/a: $71.96 \pm 17.25$; and multiracial or other:

More importantly, the interaction between sleep disturbances and VS activity was significant $(\mathrm{b}=-2.44, \mathrm{SE}=0.85, p=0.004)$. Follow-up simple slopes analysis revealed that as VS activity increased the association between sleep disturbances and depressive symptoms decreased (VS activity slopes: at $-1 \mathrm{SD}=2.44$, at the mean $=2.02$, and at $+1 \mathrm{SD}=1.60$ ). The interaction is shown in Figure 2. A region of significance analysis indicated that the regression of depressive symptoms on sleep disturbances was statistically significant for all values of VS activity that were $<0.468$ (values of centered VS activity ranged between -1.17 and 1.12). Thus, very high VS activity ( $>2$ SD above the mean) dissociated the significant association between sleep disturbances and depressive symptoms. Notably, excluding the 236 individuals with a clinical diagnosis from the sample or adding the interactions between the variables of interest and the covariates as recommended by Keller (2014) did not change the significance of the interaction between sleep disturbances and VS activity $(b=-2.67, \mathrm{SE}=$ $0.99, p=0.007 ; b=-2.08, \mathrm{SE}=0.92, p=$ 0.02 , respectively).

As post hoc analyses we tested whether one of the MASQ depression subscales was driving the results and whether the effect is specific to reward or can be explained by a more general response to feedback (i.e., the response to positive or negative feedback > control; Hariri et al., 2006). AD and GDD were analyzed separately in the same model that was used to

between CTQ and VS activity, and the interaction between LESS and VS activity were entered as covariates. Maximum likelihood estimation with robust SEs, which is robust to non-normality, was used in the regression analyses. Significant moderation effects were followed up using a web utility (http://www.yourpersonality.net/interaction) for simple slopes and region of significance (Roisman et al., 2012).

\section{Results}

\section{Descriptive statistics}

The mean value and range for each of the main variables used in our analyses are provided in Table 1.

\section{VS activity}

Consistent with earlier reports using data from subsamples of the DNS (Nikolova et al., 2012,2013; Carré et al., 2013; Corral-Frías et al., 2015; Victor et al., 2015; Baranger et al., 2016), our analyses in the final sample revealed robust bilateral reward-related VS activity from our contrast of interest (left: $x=-11, y=11, z=-7$, $t=18.07, p<0.000001, k_{\mathrm{E}}=469$; right: $x=11, y=11, z=-7, t=$ $18.08, p<0.000001, k_{\mathrm{E}}=461$; Fig. 1$)$.

\section{Depressive symptoms}

As shown in Table 2, sleep disturbances, anxiety symptoms, and early life stress predicted higher levels of depressive symptoms predict depressive symptoms (i.e., with the same covariates). The interaction between sleep disturbances and VS activity significantly predicted both GDD $(b=-1.12, \mathrm{SE}=0.36, p=0.002)$ and $\mathrm{AD}(b=-1.32$; $\mathrm{SE}=0.66, p=0.045)$, indicating that the effect is robust to both negative mood and anhedonia. The analyses of the model with either the positive feedback $>$ control or negative feedback $>$ control did not yield significant interaction effects (positive feedback $>$ control and sleep disturbances interaction: $b=1.09, \mathrm{SE}=1.06$, ns; negative feedback $>$ control and sleep disturbances interaction: $b=0.79, \mathrm{SE}=1.28, \mathrm{~ns})$, indicating that the effect is specific to reward-related VS activity (i.e., a differential response to positive feedback).

\section{Discussion}

In the current study, we show that reward-related VS activity interacts with poor sleep to predict depressive symptoms. Specifically, as VS activity increased the association between sleep disturbances and depressive symptoms decreased. The interaction between sleep disturbances and VS activity was robust to the inclusion of sex, age, race/ethnicity, past or present clinical disorder, early and recent life stress, anxiety symptoms, and their interactions with our variables-of-interest as covariates. Notably, the interaction also significantly predicted both the general dis- 
tress/depression and anhedonic depression subscales of the MASQ, thus indicating that neither set of symptoms solely accounted for the observed association.

\section{Mechanisms that may underlie the protective effect of high VS activity}

Neuroscience research on the influence of sleep disturbances has shown a general diminishment of brain activity (Thomas et al., 2000). Specifically in the VS, sleep disturbances have been shown to downregulate dopamine receptors (Volkow et al., 2012). Lower levels of dopamine have been correlated with lower activity in the VS (Robbins and Everitt, 1992), and with depression (Meyer et al., 2001). It is possible that individuals with relatively high VS activity are also characterized by initially high levels of dopamine. Consequently, these individuals may be less affected by the downregulation of dopamine that is associated with sleep disturbances, than individuals who are characterized by initially low VS activation, and possibly low levels of dopamine. In other words, in those with initially high VS activity and dopamine function, the negative effects of sleep disturbances may not decrease dopamine functionality to the levels that contribute to the development of depression.

The link between high VS activity and resilience to depressive symptoms may also reflect variability in reward-related traits, such as sensation and novelty seeking. VS activity has been shown to positively correlate with sensation seeking (Abler et al., 2006), and previous preclinical (Stedenfeld et al., 2011) and clinical (Clinton et al., 2014) research has shown that high sensation seeking confers resilience to stress and to the development of depressive symptoms. The observed link between high VS activity and resilience may further be related to the association between VS activity and optimism (Kuzmanovic et al., 2016), wherein an optimistic outlook may help individuals to cope more adaptively with poor sleep. Further research is needed to shed light on the mechanisms that underlie the protective effect of reward-related VS activity.

\section{Limitations}

The current study, of course, is not without limitations. First, only self-reported sleep quality was assessed. Future studies using laboratory-based polysomnography will be important to confirm the observed association. Second, because depression and poor sleep may have a bidirectional relationship (Bao et al., 2017) and the data used in the current study are cross-sectional, a causal inference cannot be made with certainty and needs to be tested with longitudinal data. Third, reward processing is complex and involves multiple components such as anticipation, motivation, and receipt of reward (Richards et al., 2013). The task used in this study cannot disentangle these component processes. Future studies can use tasks that are better equipped to differentiate VS activity during these various reward components and examine which may be specifically relevant to resilience. Last, the study was conducted on a group of relatively healthy young adults. Therefore, the generalizability of the findings to older and to clinical samples should be directly tested.

\section{Conclusions}

The global public health burden of depression continues to rise while effective treatment options remain limited (Mrazek et al., 2014; World Health Organization, 2017). Consequently, extensive efforts are underway to discover specific genetic and biological risk factors for depression (Clarke et al., 2010), elucidate possible environmental triggers (Van Praag, 2005), and identify depression subtypes that are resistant to treatment (Bennabi et al., 2015). Our current findings build on an accumulating research base demonstrating involvement of the VS in depression (Malone et al., 2009; Nikolova et al., 2012;
Pizzagalli, 2014; Hanson et al., 2015), by showing that high rewardrelated VS activity can decrease the strength of the association between poor sleep and depressive symptoms. Our findings further add to an emerging literature demonstrating the importance of individual differences in reward-related brain function as a potential biomarker of risk for psychopathology, and consequently support treatments that target VS activity.

\section{References}

Abela JR, Skitch SA (2007) Dysfunctional attitudes, self-esteem, and hassles: cognitive vulnerability to depression in children of affectively ill parents. Behav Res Ther 45:1127-1140. CrossRef Medline

Abler B, Walter H, Erk S, Kammerer H, Spitzer M (2006) Prediction error as a linear function of reward probability is coded in human nucleus accumbens. Neuroimage 31:790-795. CrossRef Medline

Admon R, Milad MR, Hendler T (2013) A causal model of post-traumatic stress disorder: disentangling predisposed from acquired neural abnormalities. Trends Cogn Sci 17:337-347. CrossRef Medline

Baglioni C, Battagliese G, Feige B, Spiegelhalder K, Nissen C, Voderholzer U, Lombardo C, Riemann D (2011) Insomnia as a predictor of depression: a meta-analytic evaluation of longitudinal epidemiological studies. J Affect Disord 135:10-19. CrossRef Medline

Bao YP, Han Y, Ma J, Wang RJ, Shi L, Wang TY, He J, Yue JL, Shi J, Tang XD, Lu L (2017) Cooccurrence and bidirectional prediction of sleep disturbances and depression in older adults: meta-analysis and systematic review. Neurosci Biobehav Rev 75:257-273. CrossRef Medline

Baranger DA, Ifrah C, Prather AA, Carey CE, Corral-Frías NS, Drabant Conley E, Hariri AR, Bogdan R (2016) PER1 rs3027172 genotype interacts with early life stress to predict problematic alcohol use, but not rewardrelated ventral striatum activity. Front Psychol 7:464. CrossRef Medline

Beck AT (2008) The evolution of the cognitive model of depression and its neurobiological correlates. Am J Psychiatry 165:969-977. CrossRef Medline

Bennabi D, Aouizerate B, El-Hage W, Doumy O, Moliere F, Courtet P, Nieto I, Bellivier F, Bubrovsky M, Vaiva G, Holztmann J, Bougerol T, Richieri R, Lancon C, Camus V, Saba G, Haesbaert F, d'Amato T, Charpeaud T, Llorca PM, et al. (2015) Risk factors for treatment resistance in unipolar depression: a systematic review. J Affect Disord 171:137-141. CrossRef Medline

Bernstein DP, Stein JA, Newcomb MD, Walker E, Pogge D, Ahluvalia T, Stokes J, Handelsman L, Medrano M, Desmond D, Zule W (2003) Development and validation of a brief screening version of the Childhood Trauma Questionnaire. Child Abuse Negl 27:169-190. CrossRef Medline

Bewernick BH, Hurlemann R, Matusch A, Kayser S, Grubert C, Hadrysiewicz B, Axmacher N, Lemke M, Cooper-Mahkorn D, Cohen MX, Brockmann H, Lenartz D, Sturm V, Schlaepfer TE (2010) Nucleus accumbens deep brain stimulation decreases ratings of depression and anxiety in treatmentresistant depression. Biol Psychiatry 67:110-116. CrossRef Medline

Buysse DJ, Reynolds CF 3rd, Monk TH, Berman SR, Kupfer DJ (1989) The Pittsburgh Sleep Quality Index: a new instrument for psychiatric practice and research. Psychiatry Res 28:193-213. CrossRef Medline

Carré JM, Hyde LW, Neumann CS, Viding E, Hariri AR (2013) The neural signatures of distinct psychopathic traits. Soc Neurosci 8:122-135. CrossRef Medline

Caspi A, Sugden K, Moffitt TE, Taylor A, Craig IW, Harrington HL, McClay J, Mill J, Martin J, Braithwaite A, Poulton R (2003) Influence of life stress on depression: moderation by a polymorphism in the 5-HTT gene. Science 301:386-389. CrossRef Medline

Clarke H, Flint J, Attwood AS, Munafò MR (2010) Association of the 5-HTTLPR genotype and unipolar depression: a meta-analysis. Psychol Med 40:1767-1778. CrossRef Medline

Clements K, Turpin G (1996) The life events scale for students: validation for use with British samples. Pers Individ Dif 20:747-751. CrossRef

Clinton SM, Watson SJ, Akil H (2014) High novelty-seeking rats are resilient to negative physiological effects of the early life stress. Stress 17:97107. CrossRef Medline

Corral-Frías NS, Nikolova YS, Michalski LJ, Baranger DA, Hariri AR, Bogdan R (2015) Stress-related anhedonia is associated with ventral striatum reactivity to reward and transdiagnostic psychiatric symptomatology. Psychol Med 45:2605-2617. CrossRef Medline

Corral-Frías NS, Nadel L, Fellous JM, Jacobs WJ (2016) Behavioral and selfreported sensitivity to reward are linked to stress-related differences in positive affect. Psychoneuroendocrinology 66:205-213. CrossRef Medline 
Cox RW (1996) AFNI: software for analysis and visualization of functional magnetic resonance neuroimages. Comput Biomed Res 29:162-173. CrossRef Medline

Epstein J, Pan H, Kocsis JH, Yang Y, Butler T, Chusid J, Hochberg H, Murrough J, Strohmayer E, Stern E, Silbersweig DA (2006) Lack of ventral striatal response to positive stimuli in depressed versus normal subjects. Am J Psychiatry 163:1784-1790. CrossRef Medline

Fava M, McCall WV, Krystal A, Wessel T, Rubens R, Caron J, Amato D, Roth $\mathrm{T}$ (2006) Eszopiclone co-administered with fluoxetine in patients with insomnia coexisting with major depressive disorder. Biol Psychiatry 59: 1052-1060. CrossRef Medline

First MB, Spitzer RL, Gibbon M, Williams JBM (1996) Structured clinical interview for DSM-IV Axis I disorders, research version, nonpatient edition. New York: New York State Psychiatric Institute, Biometrics Research Department.

Greve DN, Fischl B (2009) Accurate and robust brain image alignment using boundary-based registration. Neuroimage 48:63-72. CrossRef Medline

Hanson JL, Hariri AR, Williamson DE (2015) Blunted ventral striatum development in adolescence reflects emotional neglect and predicts depressive symptoms. Biol Psychiatry 78:598-605. CrossRef Medline

Hariri AR, Brown SM, Williamson DE, Flory JD, de Wit H, Manuck SB (2006) Preference for immediate over delayed rewards is associated with magnitude of ventral striatal activity. J Neurosci 26:13213-13217. CrossRef Medline

Harvey AG, Murray G, Chandler RA, Soehner A (2011) Sleep disturbance as transdiagnostic: consideration of neurobiological mechanisms. Clin Psychol Rev 31:225-235. CrossRef Medline

Keller MC (2014) Gene $\times$ environment interaction studies have not properly controlled for potential confounders: the problem and the (simple) solution. Biol Psychiatry 75:18-24. CrossRef Medline

Klein A, Andersson J, Ardekani BA, Ashburner J, Avants B, Chiang M-C, Christensen GE, Collins DL, Gee J, Hellier P, Song JH, Jenkinson M, Lepage C, Rueckert D, Thompson P, Vercauteren T, Woods RP, Mann JJ, Parsey RV (2009) Evaluation of 14 nonlinear deformation algorithms applied to human brain MRI registration. Neuroimage 46:786-802. CrossRef Medline

Kuzmanovic B, Jefferson A, Vogeley K (2016) The role of the neural reward circuitry in self-referential optimistic belief updates. Neuroimage 133: 151-162. CrossRef Medline

Lecrubier Y, Sheehan DV, Weiller E, Amorim P, Bonora I, Sheehan KH, Janavs J, Dunbar GC (1997) The Mini International Neuropsychiatric Interview (MINI). A short diagnostic structured interview: reliability and validity according to the CIDI. Eur Psychiatry 12:224-231. CrossRef

Malone DA, Dougherty DD, Rezai AR, Carpenter LL, Friehs GM, Eskandar EN, Rauch SL, Rasmussen SA, Machado AG, Kubu CS, Tyrka AR, Price LH, Stypulkowski PH, Giftakis JE, Rise MT, Malloy PF, Salloway SP, Greenberg BD (2009) Deep brain stimulation of the ventral capsule/ ventral striatum for treatment-resistant depression. Biol Psychiatry 65: 267-275. CrossRef Medline

Manber R, Chambers AS (2009) Insomnia and depression: a multifaceted interplay. Curr Psychiatry Rep 11:437-442. CrossRef Medline

Manber R, Edinger JD, Gress JL, San Pedro-Salcedo MG, Kuo TF, Kalista T (2008) Cognitive behavioral therapy for insomnia enhances depression outcome in patients with comorbid major depressive disorder and insomnia. Sleep 31:489-495. CrossRef Medline

Meyer JH, Krüger S, Wilson AA, Christensen BK, Goulding VS, Schaffer A, Minifie C, Houle S, Hussey D, Kennedy SH (2001) Lower dopamine transporter binding potential in striatum during depression. Neuroreport 12:4121-4125. CrossRef Medline

Mrazek DA, Hornberger JC, Altar CA, Degtiar I (2014) A review of the clinical, economic, and societal burden of treatment-resistant depression: 1996-2013. Psychiatr Serv 65:977-987. CrossRef Medline

Muthén LK, Muthén BO (2007) Mplus user’s guide. Los Angeles: Muthén and Muthén.

Nichols TE (2017) Notes on creating a standardized version of DVARS. arXiv. Advanced online publication. arXiv:1704.01469. Retrieved June 19, 2017.

Nikolova YS, Bogdan R, Brigidi BD, Hariri AR (2012) Ventral striatum reactivity to reward and recent life stress interact to predict positive affect. Biol Psychiatry 72:157-163. CrossRef Medline

Nikolova YS, Singhi EK, Drabant EM, Hariri AR (2013) Reward-related ventral striatum reactivity mediates gender-specific effects of a galanin remote enhancer haplotype on problem drinking. Genes Brain Behav 12: 516-524. CrossRef Medline

Pizzagalli DA (2014) Depression, stress, and anhedonia: toward a synthesis and integrated model. Annu Rev Clin Psychol 10:393-423. CrossRef Medline

Power JD, Mitra A, Laumann TO, Snyder AZ, Schlaggar BL, Petersen SE (2014) Methods to detect, characterize, and remove motion artifact in resting state fMRI. Neuroimage 84:320-341. CrossRef Medline

Prather AA, Bogdan R, Hariri AR (2013) Impact of sleep quality on amygdala reactivity, negative affect, and perceived stress. Psychosom Med 75:350-358. CrossRef Medline

Purcell S, Neale B, Todd-Brown K, Thomas L, Ferreira MA, Bender D, Maller J, Sklar P, de Bakker PI, Daly MJ, Sham PC (2007) PLINK: a tool set for whole-genome association and population-based linkage analyses. Am J Hum Genet 81:559-575. CrossRef Medline

Richards JM, Plate RC, Ernst M (2013) A systematic review of fMRI reward paradigms used in studies of adolescents vs. adults: the impact of task design and implications for understanding neurodevelopment. Neurosci Biobehav Rev 37:976-991. CrossRef Medline

Robbins TW, Everitt BJ (1992) Functions of dopamine in the dorsal and ventral striatum. Semin Neurosci 4:119-127. CrossRef

Roisman GI, Newman DA, Fraley RC, Haltigan JD, Groh AM, Haydon KC (2012) Distinguishing differential susceptibility from diathesis-stress: recommendations for evaluating interaction effects. Dev Psychopathol 24:389-409. CrossRef Medline

Schlaepfer TE, Cohen MX, Frick C, Kosel M, Brodesser D, Axmacher N, Joe AY, Kreft M, Lenartz D, Sturm V (2008) Deep brain stimulation to reward circuitry alleviates anhedonia in refractory major depression. Neuropsychopharmacology 33:368-377. CrossRef Medline

Sofi F, Cesari F, Casini A, Macchi C, Abbate R, Gensini GF (2014) Insomnia and risk of cardiovascular disease: a meta-analysis. Eur J Prev Cardiol 21:57-64. CrossRef Medline

Stedenfeld KA, Clinton SM, Kerman IA, Akil H, Watson SJ, Sved AF (2011) Novelty-seeking behavior predicts vulnerability in a rodent model of depression. Physiol Behav 103:210-216. CrossRef Medline

Strawn JR, Dominick KC, Patino LR, Doyle CD, Picard LS, Phan KL (2014) Neurobiology of pediatric anxiety disorders. Curr Behav Neurosci Rep 1:154-160. CrossRef Medline

Swartz JR, Knodt AR, Radtke SR, Hariri AR (2015) A neural biomarker of psychological vulnerability to future life stress. Neuron 85:505-511. CrossRef Medline

Taylor DJ, Lichstein KL, Durrence HH (2003) Insomnia as a health risk factor. Behav Sleep Med 1:227-247. CrossRef Medline

Thomas M, Sing H, Belenky G, Holcomb H, Mayberg H, Dannals R, Wagner H, Thorne D, Popp K, Rowland L, Welsh A, Balwinski S, Redmond D (2000) Neural basis of alertness and cognitive performance impairments during sleepiness: I. Effects of $24 \mathrm{~h}$ of sleep deprivation on waking human regional brain activity. J Sleep Res 9:335-352. CrossRef Medline

Van Praag HM (2005) Can stress cause depression? World J Biol Psychiatry 6:5-22. CrossRef Medline

Victor EC, Sansosti AA, Bowman HC, Hariri AR (2015) Differential patterns of amygdala and ventral striatum activation predict gender-specific changes in sexual risk behavior. J Neurosci 35:8896-8900. CrossRef Medline

Viviani R (2010) Unbiased ROI selection in neuroimaging studies of individual differences. Neuroimage 50:184-189. CrossRef Medline

Volkow ND, Tomasi D, Wang GJ, Telang F, Fowler JS, Logan J, Benveniste H, Kim R, Thanos PK, Ferré S (2012) Evidence that sleep deprivation downregulates dopamine $\mathrm{D} 2 \mathrm{R}$ in ventral striatum in the human brain. J Neurosci 32:6711-6717. CrossRef Medline

Wang X, Cai L, Qian J, Peng J (2014) Social support moderates stress effects on depression. Int J Ment Health Syst 8:41. CrossRef Medline

Watson D, Clark LA (1991) The mood and anxiety symptom questionnaire. Unpublished manuscript, University of Iowa, Department of Psychology, Iowa City, IA.

Whiteford HA, Degenhardt L, Rehm J, Baxter AJ, Ferrari AJ, Erskine HE, Charlson FJ, Norman RE, Flaxman AD, Johns N, Burstein R, Murray CJ, Vos T (2013) Global burden of disease attributable to mental and substance use disorders: findings from the Global Burden of Disease Study 2010. Lancet 382:1575-1586. CrossRef Medline

World Health Organization (2017) Depression: fact sheet. Available from: http://www.who.int/mediacentre/factsheets/fs369/en/. 